\title{
Correlation between Apgar score and hipoxic-ischemic encephalopathy
}

\section{Correlação entre escore de Apgar e encefalopatia hipóxico-ISQuÊmica}

José M. R. Perez ${ }^{1}$

1PM.D., Coordinator, Centro Internacional de Neurodesenvolvimento Neonatal (CINN), Secretary at the Sociedade Iberoamericana de Neonatologia (Siben). São Paulo, SP, Brazil.

joseperezneo@gmail.com

After the publication of articles such as those of Salustiano et al. ${ }^{1}$ and Ehrenstein et al., ${ }^{2}$ demonstrating the strong association between low Apgar score ( $<7)$ at 5 minutes and the incidence of hypoxic-ischemic encephalopathy (HIE) leading to cerebral palsy; and also on account of our experience in the management of patients with HIE, as published by Perez et al., ${ }^{3}$ and our experience in noting the difficulty in diagnosing this condition in the countries of Latin America, as reported by the Ibero-American Society of Neonatology (Siben), we decided to put into debate a proposal for monitoring of newborns presenting perinatal asphyxia.

As we can see in these studies ${ }^{1,2}$ the incidence of HIE is much higher than the already published in Latin American studies. This can be partly explained by population differences, but also for the association between low Apgar and HIE. In our specialty, it is relatively common to find centers that keep newborns with low Apgar score at 1 or 5 minutes, but who recover at 10 minutes, in the nursery, without monitoring their neurological progress more thoroughly, missing the opportunity for early diagnosis of HIE. In our previously cited study, ${ }^{3}$ we made a change in the routine assessment of our newborns with Apgar score 5 or less at any time of evaluation (1'-5'-10') by implementing an additional clinical assessment using the Sarnat neurological score at 10 minutes after birth and hourly thereafter within the first six hours of life, a critical period for decision-making, regarding deployment of therapeutic hypothermia. This should be done in all newborns even when there is recovery according to Apgar score, because the hypoxic ischemic injury might already have triggered the inflammatory process that may result in HIE. As a result of this strategy, we had an incidence of neurological sequelae of $11.5 \%$ ( 3 cases in 26 newborns with moderate to severe HIE; 1 with mild cerebral palsy, 1 with moderate cerebral palsy and 1 with hearing deficit; no severe cerebral palsy), which is very low in our context for patients with HIE.

One of the main difficulties encountered initially to implement this routine was training to use the said score. Both the medical and nursing staffs were not familiar with the scale, which, unfortunately, is common in most Latin American countries. Too often we find centers that do not use any neurological grading scale to evaluate newborns, and the question remains as to how they will be able to identify cases of HIE disease. In our study, we chose to print the Sarnat score and put it on the wall in places that included the delivery room and the intermediate care and intensive care units, and to prepare a specific training for doctors and nurses on the score.

Today, as the formation of therapeutic hypothermia centers in Latin America is encouraged, we emphasize the need to adapt the training of newborn care teams toward proper diagnosis, without which the efficacy of any therapy is compromised.

\section{References}

1. Salustiano EMA, Campos JADB, Ibidi SM, Ruano R, Zugaib M. Low Apgar score at 5 minutes in a low risk population: maternal and obstetrical factors and postnatal outcomes. Rev Assoc Med Bras. 2012; 58(5):587-93.

2. Ehrenstein V, Pedersen L, Grijota M, Nielsen GL, Rothman KJ, Toft H Association of Apgar score at five minutes with long-term neurologic disability and cognitive function in a prevalence study of Danish conscripts. BMC Pregnancy Childbirth. 2009; 9:14.

3. Perez JMR, Golombek S, Sola A, Alpan G. A novel device for the treatment of neonatal hypoxic encephalopathy with hypothermia: neonatal laminar flow unit. Acta Paediatrica. In press. 